\title{
MICROBIOLOGIA NO ENSINO FUNDAMENTAL: COMO OS LIVROS DIDÁTICOS ABORDAM ESSA TEMÁTICA
}

\section{MICROBIOLOGY IN ELEMENTARY SCHOOL: HOW TEXTBOOKS ADDRESS THIS THEME}

\author{
Gizele Tiago Barbêdo ${ }^{1}$, Carlos Alberto Andrade Monerat ${ }^{2}$ \\ ${ }^{1}$ Centro Universitário Celso Lisboa/gizele.tiago@gmail.com \\ ${ }^{2}$ Centro Universitário Celso Lisboa/cmonerat@ig.com.br
}

\begin{abstract}
RESUMO
Propor atividades capazes de promover a construção do conhecimento discente, estimulando um pensamento crítico e aprendizado significativo, torna-se cada vez mais oportuno. Aulas experimentais permitem relacionar prática e teoria, além de aperfeiçoar habilidades e permitir melhor compreensão do conteúdo programático. O livro didático pode ajudar neste processo por oferecer sugestões experimentais que auxiliem o planejamento docente. $\mathrm{O}$ objetivo desta pesquisa é analisar as sugestões de atividades experimentais contidas nos livros didáticos referentes à microbiologia, visando a melhoria no ensino de ciências. Após a avaliação foi possível perceber que tais obras apresentam ideias construtivas aos docentes, porém a busca por atividades complementares pode ser algo positivo visando obter maior eficácia no processo de ensino. Apesar de fatores restritivos, a aplicação de aulas práticas experimentais pode ser de grande valia para que haja a promoção da construção do saber do aluno e não apenas a simples memorização de informações.
\end{abstract}

Palavras-chave: Atividades experimentais; Microrganismos; Livro didático; Ensino fundamental.

\begin{abstract}
To propose activities what make possible to promote student knowledge construction, stimulating a critical thinking and a meaningful learning, becomes much more suitable. Experimental classes allow connect practical and theory, besides improve skills and permit better understanding of the program content. The textbook can support on this process offering experimental suggestions that help the teacher planning. The aim of this research is analyses the experimental activities suggestions on the textbooks related to the microbiology, aimed at improving the science learning. After the evaluation was possible to realize that such works shows constructive ideas to the teachers, however the search for complementary activities can be something positive aimed to obtain more effectiveness on the teaching process. Despite of the restrictive factors, the practical classes application can mean a great value to there the student knowledge construction and not only memorizing of information.
\end{abstract}

Key words: Experimental activities; Microorganisms; Textbook; Elementary teaching. 


\section{INTRODUÇÃO}

Descobrir explicações para os fenômenos da natureza, para as doenças e para os enigmas da vida é algo que há muito tem permeado a existência do ser humano. Estes questionamentos impulsionaram grandes avanços científicos e tecnológicos ao longo da história e a procura incessante por explicações para o que ocorre à nossa volta foi o que originou a Ciência.

Dentro das Ciências Naturais ou da Natureza, há um campo que estuda os seres microscópicos, denominado Microbiologia. Tais seres podem ser classificados em celulares: bactérias, arqueas, algas, protozoários e fungos; e acelulares: vírus, viróides e príons. A maioria destes organismos não é patogênica e o homem, através de estudos científicos, descobriu como obter benefícios a partir deles (WALTER \& BARRA, 2001).

Por serem invisíveis a olho nu, aceitar a existência de tais organismos pode tornar-se algo complexo para aqueles que iniciam o aprendizado científico. Algumas escolas possuem laboratórios equipados com microscópios ópticos que permitem a visualização de microrganismos, porém nem todos os locais desfrutam deste mesmo benefício.

Para os espaços escolares desprovidos de equipamentos que permitam observação microscópica, as aulas experimentais ou práticas podem ser capazes de estimular a curiosidade do aluno, desenvolver a capacidade de resolução de problemas, aperfeiçoar habilidades, além de permitir uma melhor compreensão do conteúdo programático. Através deste processo, o aprendiz pode ter acesso a fenômenos, visualizar pequenos organismos e entrar em contato com instrumentos participantes da rotina laboratorial (KRASILCHICK, 1983).

Segundo Araújo et al, 2011, o uso de experimentos nas unidades escolares tem por intuito aperfeiçoar a aprendizagem dos alunos, visto que apenas guardavam conceitos teóricos, mas não sabiam como aplicá-los. Este conceito perdura até os dias de hoje e a experimentação continua sendo usada com o propósito de relacionar conceitos aprendidos ao longo da vida escolar com a prática.

Embora o ensino experimental seja de grande valia no ambiente escolar, pode ser dificultosa a sua existência sem que haja material complementar para embasar sua aplicação. Tais conceitos são encontrados no livro didático que é um guia muito 
utilizado no decorrer dos anos por discentes e docentes, tanto no Ensino Fundamental, como em todos os outros níveis de formação acadêmica.

O livro didático é uma importante ferramenta pedagógica no ensino de Ciências, especialmente por possuir atribuições que o difere dos demais quanto a empregar o método científico e incentivar o espírito investigativo do aprendiz (VASCONCELOS \& SOUTO, 2003).

Visando seu aprimoramento, foram criados diversos programas, ao longo das décadas, para regulamentar a utilização deste instrumento pedagógico. Inicialmente, preocupava-se apenas com a correção de possíveis falhas de conteúdo, porém, atualmente, para acompanhar o movimento denominado "Escola Nova" foi necessário a reavaliação de critérios, pois percebeu-se que o aluno precisa ser um sujeito ativo e não passivo em termos de aprendizagem (BRASIL, 1998).

Devido a este fato, os parâmetros hoje utilizados são alicerçados em metodologias que incentivem atividades experimentais exploratórias, permitindo o encontro com a verdadeira pesquisa científica (BRASIL, 2013). O livro didático se configura em uma espécie de manual e tem por objetivo aperfeiçoar o padrão de ensino levando em conta a inter-relação entre sociedade, Ciência e Tecnologia e sua influência sobre a natureza e os seres vivos que nela habitam. O lecionando deve ser alguém capaz de expor seu próprio ponto de vista e apto a responder questionamentos que porventura venham a surgir na prática da atividade experimental (ARAÚJO et al, 2011).

Desta maneira, esta pesquisa tem como objetivo analisar as sugestões de atividades experimentais contidas nos livros didáticos referentes à microbiologia, relacionando-as ao uso em sala de aula para uma melhoria na qualidade do ensino de Ciências.

\section{METODOLOGIA}

A pesquisa aqui apresentada foi baseada na análise do conteúdo de livros didáticos relacionados a microrganismos com enfoque nas sugestões propostas de atividades experimentais. Ludwig (2009) define a pesquisa bibliográfica como a ação de buscar, colher, observar, interpretar e julgar as colaborações teóricas pré-existentes sobre determinado assunto.

Este trabalho apresenta-se fundamentado em uma pesquisa exploratória de caráter qualitativo. Conforme explicitado por Cajueiro (2012), para que um estudo tenha cunho exploratório é necessário aprofundar o conhecimento ou levantar informações 
relacionadas a determinadas questões suscitadas que permitam a criação de hipóteses, sem deixar de avaliar a qualidade ou padrão de informação contido no material a ser analisado, pois é baseado na compreensão do subjetivo ou situações que exijam interpretação.

Os exemplares didáticos examinados integram o material de apoio pedagógico do $7^{\circ}$ ano do Ensino Fundamental. O objeto principal de observação é a seção que trata da abordagem do conteúdo de microbiologia. As obras selecionadas estão discriminadas a seguir: Pereira et al. (2009) - Livro de Ciências para o $7^{\circ}$ ano, volume 2 - Coleção Perspectiva da Editora do Brasil; Canto (2009) - Livro de Ciências Naturais: aprendendo com o cotidiano para o $7^{\circ}$ ano da editora Moderna.; Barros \& Paulino (2009) - Livro de Ciências dos seres vivos utilizado no $7^{\circ}$ ano da editora Ática; Cruz (Ed.) (2006) - Livro de Ciências do Projeto Araribá, para 6 ${ }^{a}$ série da editora Moderna; Gewandsznajder (2012) - Livro de Ciências para o $7^{\circ}$ ano do Projeto Teláris da editora Ática e Gowdak \& Martins (2012) - Livro de Ciências dos seres vivos para o $7^{\circ}$ ano da coleção Novo Pensar da editora FTD.

\section{ANÁLISE E DISCUSSÃo DOS DADOS}

$1^{\circ}$ LIVRO - PEREIRA ET AL. (2009) - LIVRO DE CIÊNCIAS PARA O $7^{\circ}$ ANO, VOLUME 2 - COLEÇÃO PERSPECTIVA; EDITORA DO BRASIL.

Após leitura do conteúdo apresentado na unidade dois, encontrou-se apenas uma sugestão de experimentação no capítulo referente ao estudo dos fungos. A experiência sugerida utiliza até materiais de fácil aquisição, demonstrando situações do cotidiano, porém possui apenas caráter demonstrativo, não traz sugestões de questões problematizadoras.

Quanto à utilização de situações do cotidiano do aluno na abordagem experimental, a obra organizada por Nardi (2010), inferiu, depois de pesquisas realizadas, que atividades experimentais relacionadas com temas presentes no dia a dia do educando são recomendadas por vários autores, visto que permitem a contextualização e a motivação do mesmo, permitindo um aprendizado prazeroso e eficaz.

$\mathrm{Na}$ abordagem sobre o reino Monera, experimentos poderiam ter sido sugeridos, tanto no início como no final do capítulo. No início para promover questionamentos, estimular a curiosidade, incitando a busca por novas informações, que 
poderiam ser elucidadas no decorrer do capítulo e ao final para realizar uma análise mais aprofundada, já com a bagagem adquirida de práticas anteriores.

A obra examinada é rica em conteúdos teóricos e isto pode tornar sua leitura um pouco desestimulante. Não há cadernos de atividades experimentais complementares e nem sugestões no manual do professor. Desta forma seria interessante a busca por outras sugestões em material didático complementar.

Conforme Marandino et al (2009) é bem comum ouvir nos ambientes escolares que o conteúdo teórico não pode ser deixado de lado por causa de aulas práticas, porém este conceito pode atribuir a tais atividades um caráter secundário, desnecessário ou até mesmo dispensável, porém a aplicação de tal metodologia possui papel importante no processo educativo como forma de relacionar o saber empírico do aluno com o saber científico, de maneira que a edificação do seu conhecimento seja algo concreto e duradouro.

\section{$\mathbf{2}^{\mathbf{0}}$ LIVRO - CANTO (2009) - LIVRO DE CIÊNCIAS NATURAIS: APRENDENDO COM O COTIDIANO PARA O $7^{\circ}$ ANO DA EDITORA MODERNA.}

Feita análise da seção de interesse, observou-se uma atividade relacionada à vida dos fungos, apresentando no princípio um experimento concernente ao metabolismo micótico e ao final outro demonstrando a presença destes microrganismos em todos os ambientes, bem como seu crescimento, utilizando componentes de fácil obtenção e simples de serem produzidos. Tal posicionamento pode ser interessante, pois como dito anteriormente, aguça a criatividade do aluno e permite a interligação de informações. Marandino et al (2009) defende a aplicação de atividades experimentais não somente após a unidade temática, mas também antes, pois tal colocação provocará questionamentos, permitindo a orientação do aprendizado discente.

No entanto, para estimular o espírito investigativo e a formulação de hipóteses, seria interessante a colocação de uma questão norteadora. As atividades experimentais precisam partir de um problema, cabendo ao professor a tarefa de guiar o aluno na busca por soluções, propondo questionamentos que permitam o levantamento de hipóteses, a organização dos resultados obtidos após a análise dos resultados, utilizando as conclusões tiradas para construir seu aprendizado (BRASIL, 2006).

Quanto à abordagem referente ao reino Monera, observou-se que o conteúdo é restrito e trata apenas da morfologia e reprodução bacteriana. Não foi encontrado nenhum tipo de atividade experimental, sendo extremamente importante sua inclusão, 
visto que possibilitaria uma melhor compreensão do assunto. Para compensar esta deficiência seria necessária uma intervenção docente, por buscar ou criar modelos de atividades experimentais para serem aplicadas em sala de aula.

O livro possui um caderno de suplemento de projetos com diversas práticas experimentais a serem realizadas pelos estudantes, porém só há uma sugestão relacionada ao crescimento dos fungos. A introdução de experimentos extras que contivessem exercícios experimentais demonstrando a atividade bacteriana em questões de saúde, como a lavagem correta das mãos, a localização destes seres em nosso organismo integrando nossa flora biológica e sua participação na degradação de substâncias, poderiam ser bem interessantes. Utilizar tais recursos possibilita uma melhor compreensão do mundo ao redor e da importância de nossa interação com estes pequenos organismos.

$3^{\text {o }}$ LIVRO - BARROS \& PAULINO (2009) - LIVRO DE CIÊNCIAS DOS SERES VIVOS PARA O $7^{\circ}$ ANO DA EDITORA ÁTICA.

No trecho da obra que trata de microrganismos foi possível encontrar somente sugestões experimentais relacionadas ao crescimento e metabolismo de fungos e bactérias ao final da unidade dois, sob os seguintes temas: "Fabricando iogurte" e "Fabricando pão". Demonstram como são produzidos, passo a passo, iogurte e pão, utilizando materiais acessíveis e situações familiares.

A princípio aparenta ter um caráter apenas demonstrativo, posteriormente, em outro quadro percebe-se perguntas relativas ao procedimento realizado, buscando obter a opinião do aluno com relação a que grupo de microrganismos possibilitou a formação do iogurte e do pão e ainda que processo permite o crescimento da massa, no caso da fabricação do pão. Tais questionamentos são interessantes, porém talvez fossem mais vantajosos, se aplicados ao início de cada capítulo, visto que todos os dados encontrados ao final do experimento já estão respondidos no decorrer do assunto que trata de cada reino.

Ao docente, neste caso, cabe a condução do processo de forma a planejar a aplicação das sugestões apresentadas anteriormente ao início do capítulo, abrindo espaço para os estudantes analisarem a situação e levantarem hipóteses acerca do assunto tratado, permitindo-os raciocinar, levando-os a busca posterior por informações científicas a fim de comparar com as conclusões alcançadas (MARANDINO et al, 2009).

Edição Especial com os melhores trabalhos apresentados no IV ENECiências: UFF - 13 a 16 de 6 maio de 2014. 


\section{Ensino, Saúde e Ambiente - V 7 (1), Edição Especial, maio de 2014}

Ainda referindo-se a este mesmo suplemento, observou-se a presença de mais duas atividades complementares a serem utilizadas a critério do professor, que apresentam sugestões construtivas e problematizadoras, objetivando obter maior eficácia no processo de ensino.

Segundo Marandino et al (2009), ao planejar a aplicação de atividades práticas o professor deve sempre se perguntar se tal exercício irá auxiliar seus alunos a entenderem o tema abordado, de que maneiras é possível despertar sua curiosidade a partir da realização de tal tarefa e de que formas a atividade proposta irá instigá-los a levantar questões relativas ao assunto.

A primeira atividade apresentada no caderno suplementar aborda o crescimento e metabolismo das leveduras, tendo como recomendação dos autores o incentivo aos alunos em expor suas opiniões acerca dos resultados encontrados após execução do experimento. A segunda também trata do crescimento das mesmas, porém inclui a relação que a temperatura tem com a sobrevivência destes organismos. A proposta apresentada é bastante proveitosa, pois recomenda anteriormente a execução da atividade, um questionamento acerca do tema que está sendo tratado, incitando o espírito de curiosidade do aprendiz.

No entanto, a fim de tornar a atividade prática mais eficaz, o instrutor pode, antes de iniciar o procedimento, indagar a opinião dos alunos sobre como é realizada a fabricação do pão e o crescimento da massa, executar o exercício e discutir os resultados, posteriormente comparando-os com as informações contidas no livro.

A atividade sugerida no manual do professor relacionando a temperatura ao crescimento de leveduras pode ser utilizada para complementar a prática da fabricação do pão. Pode-se começar utilizando a sugestão de problematização do livro, realizar os experimentos e após isso deixar os alunos tirarem suas conclusões acerca do resultado obtido. Os autores aconselham informar que as leveduras não estão mais vivas após assar o pão, antes mesmo da conferência do resultado do experimento. Tal ação não seria ideal, pois não haveria mais necessidade de raciocinar ou questionar o acontecido, a resolução do problema já estaria dada.

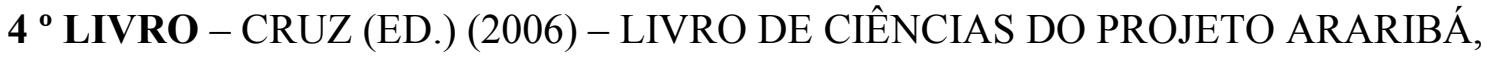
PARA $6^{a}$ SÉRIE DA EDITORA MODERNA.

Ao analisar os capítulos que abordam a respeito da vida microscópica, foi observado apenas um experimento que tem por finalidade demonstrar como os fungos Edição Especial com os melhores trabalhos apresentados no IV ENECiências: UFF - 13 a 16 de 7 maio de 2014. 
realizam a decomposição de matéria orgânica, porém tal sugestão tem pouco destaque, podendo até mesmo passar despercebida. Embora utilize um fenômeno que ocorre constantemente e faz parte do cotidiano, poderia ser mais bem explorado ao suscitar questões visando obter a opinião do aluno com respeito ao assunto a ser tratado, antes de iniciar a execução da atividade.

Como o resultado do experimento não é imediato e requer tempo para chegar a um processo conclusivo, sugere-se que o orientador peça aos alunos que observem e registrem diariamente as mudanças ocorridas com o pão, podendo utilizar também desenhos demonstrativos para representar o progresso apresentado e ao final do procedimento, apresentar um parecer do que realmente aconteceu com o alimento em questão, assim como sugerido no material didático, comparando posteriormente com o princípio científico e com outros processos de decomposição.

Como afirmam Vasconcelos \& Souto (2003), atividades experimentais oferecem ao aluno uma oportunidade de elaborar e testar suas opiniões, além de reunir informações, possibilitado chegar a conclusões fundamentadas na fonte bibliográfica referente ao tema.

Ao final do instrumento de apoio pedagógico em questão há um caderno complementar denominado "Oficinas de Ciências". Nele são propostos alguns experimentos relacionados aos microrganismos. A primeira sugestão que aborda a vida microscópica refere-se a oficina quatro e intitula-se: “Observando lactobacilos”. Tal proposta visa demonstrar o processo de fermentação realizado por bactérias na produção de coalhada e as formas bacterianas participantes do processo, em microscópio óptico, porém vale a pena lembrar que nem todas as escolas dispõem deste recurso, de modo que nem sempre é possível a visualização dos lactobacilos contidos no experimento, sendo assim, a prática experimental pode ser uma forma de apresentar ao aluno, como estes microrganismos atuam na produção de determinados alimentos.

A oficina cinco possui como título "Observando atividades dos fungos". Tratase de uma atividade que tem como propósito a preparação da massa do pão e observação da ação das leveduras neste processo. Sugere-se produzir dois tipos diferentes de massa, uma com fermento biológico e outra sem nenhum tipo de fermento, deixar em repouso e comparar os resultados. As atividades propostas logo após a realização do método podem ser bem propícias, pois permitem uma análise dos fatos conduzindo a reflexão discente diante dos resultados do procedimento efetuado. 
De acordo com Borges (2002), as atividades práticas podem proporcionar aos alunos imagens reais e inesquecíveis de fatos cativantes e relevantes para o real entendimento dos princípios científicos.

\section{$5^{\circ}$ LIVRO - GEWANDSZNAJDER (2012) - LIVRO DE CIÊNCIAS PARA O $7^{\circ}$ ANO DO PROJETO TELÁRIS DA EDITORA ÁTICA.}

Foram encontradas neste exemplar, duas atividades práticas, no trecho que trata dos microrganismos. Pretendem expor a ação dos fungos como agentes decompositores e fermentadores e incentivar sua visualização em microscópio óptico. Mesmo que certos ambientes escolares não disponibilizem este recurso, algumas regiões possuem centros de Ciências ou museus que possuem este artefato e o concedem para este fim. Cabe ao professor avaliar a viabilidade do exercício em questão.

As questões sugeridas no texto são bastante proveitosas, pois visam auxiliar o docente no direcionamento da atividade, sendo capazes de proporcionar uma melhor compreensão dos fenômenos ocorridos na realização do experimento de modo a comparar conceitos científicos a situações comuns da vida.

A fim de que não se perca o real objetivo da aula prática, é essencial a intervenção do professor quanto à orientação dada ao aluno acerca das hipóteses por ele levantadas, para isso o planejamento é fundamental. Após pesquisas realizadas, Marandino et al (2009) percebeu que as aulas de Ciências baseadas em experimentos didáticos possuem maior enriquecimento quando as indagações despertadas nos alunos por estes exercícios são alvo de atenção por parte do educador.

Não estão presentes neste exemplar, nem no manual do professor, nem em caderno suplementar outras sugestões de aulas práticas experimentais, de modo que fica a cargo do professor, se assim desejar, buscar outras fontes de complementação.

\section{$6^{\circ}$ LIVRO - GOWDAK \& MARTINS (2012) - LIVRO DE CIÊNCIAS DOS SERES VIVOS PARA O $7^{\circ}$ ANO DA COLEÇÃO NOVO PENSAR DA EDITORA FTD.}

As atividades práticas sugeridas na obra analisado são de fácil execução, com materiais acessíveis e participantes da realidade do aluno. Apresentam sugestões de forma a auxiliar o docente na melhor utilização das práticas experimentais, visando uma maior produtividade ao ensinar os conceitos relacionados aos microrganismos.

Segundo Borges (2002), a aplicação de atividades experimentais não deve se prender somente a um laboratório ou local específico para sua realização, o fator de 
maior importância, na realidade, é um planejamento bem feito e clareza de objetivos nas atividades apresentadas.

O primeiro experimento realizado refere-se ao reino Monera e busca facilitar a percepção, através da análise dos resultados obtidos, do crescimento bacteriano bem como a influência que a temperatura exerce neste processo. $O$ autor incentiva $o$ estudante, no exercício proposto, a expressar suas possíveis hipóteses acerca dos acontecimentos ocorridos durante a realização do procedimento, estimula anotações diárias acompanhadas de desenhos a fim de relatar o progresso observado, concluindo com indagações que tem por intuito estimular a capacidade de raciocínio do aluno. Convida-o também a comparar os resultados obtidos com as hipóteses por ele levantadas no início da atividade. Para aguçar a curiosidade discente seria interessante aplicar esta atividade anteriormente aos conceitos teóricos, necessitando assim, de planejamento docente de acordo com o objetivo que se pretende alcançar.

Há presença de mais dois experimentos que tratam do desenvolvimento dos fungos e seu metabolismo. O primeiro visa auxiliar no entendimento de sua atuação como agentes decompositores, incentivando o questionamento acerca do resultado que se pretende atingir, bem como um relato diário descrevendo as modificações ocorridas com os materiais selecionados para estudo. A tarefa é finalizada com questões problematizadoras a serem respondidas pelo aluno com relação ao produto final resultante do experimento.

A segunda prática auxilia no entendimento acerca do processo fermentativo realizado pelas leveduras, uma espécie de fungo. Este exercício possui a mesma linha de raciocínio dos demais, porém a relação entre o crescimento das leveduras e a temperatura poderia ser mais explorada.

Não foram encontradas, no manual do professor, sugestões complementares relacionadas a atividades práticas.

Todas as sugestões apresentadas necessitam de intervenção docente tanto na organização como no direcionamento da atividade a fim de que o ensino acerca dos microrganismos seja atraente, passando uma visão real de sua existência e não apenas a de figuras imaginárias presentes na mente dos aprendizes.

\section{CONSIDERAÇÕES FINAIS}

O planejamento docente é algo essencial na aplicação de aulas práticas, visto que o professor deve adequá-las as necessidades de sua turma, sempre procurando Edição Especial com os melhores trabalhos apresentados no IV ENECiências: UFF - 13 a 16 de 10 maio de 2014. 
informações adicionais enriquecedoras no processo de ensinar as Ciências dos microrganismos de maneira estimulante e construtiva, a fim de obter maior eficácia na compreensão dos conceitos e da interação destes seres microscópicos com o meio ambiente e com o ser humano.

Introduzir aulas práticas no ambiente escolar, não é tarefa fácil, pois existem diversos fatores limitantes. Não são todas as instituições educacionais que possuem laboratórios ou recursos para efetuar tal processo. Mesmo assim, de acordo com Marandino et al (2009), muitos professores ainda conseguem superar estes obstáculos produzindo atividades criativas, quebrando desta forma, o total silêncio, por assim dizer, das atividades experimentais no ensino de Ciências.

As que possuem tais recursos, muitas vezes enfrentam outros tipos dificuldades. Conforme análise de Marandino et al (2009), várias escolas até possuem um laboratório instalado, mesmo assim, atividades práticas são esporádicas e visitar este local constitui apenas em algo que tem por objetivo "quebrar a rotina" das costumeiras aulas expositivas. Ainda segundo a mesma autora observando esta realidade é possível perceber que o principal motivo para que as aulas práticas não sejam ministradas, estão relacionadas com a organização estrutural, o curto período de tempo, a insegurança por parte do professor em aplicá-las e a possível perda de controle devido a um grande número de alunos dentro do laboratório.

Apesar dos fatores restritivos, a inclusão de aulas práticas experimentais no planejamento docente é algo bastante proveitoso visto que sua aplicação permite aos discentes articular a teoria e a prática de forma prazerosa, o que permitirá descobrir novos rumos por meio de sua reflexão crítica, contribuindo para seu crescimento e para a construção de um aprendizado real e significativo.

\section{REFERÊNCIAS BIBLIOGRÁFICAS}

ARAÚJO, M. F. F; SOUSA, R.A; SOUSA, I.C. Instrumentação para o ensino de Biologia II. 2. ed. Natal: EDUFRN, 2011.

BARROS, C.; PAULINO, W.R. Ciências: os seres vivos, $7^{\circ}$ ano. 4. ed. São Paulo: Ática, 2009.

BORGES, A.T. Novos rumos para o laboratório escolar de Ciências. Caderno Brasileiro de Ensino de Física. Florianópolis, Santa Catarina.v.19, n.3, p. 291-313, 2002. 
BRASIL. Secretaria de Educação Fundamental. Parâmetros Curriculares Nacionais: Ciências Naturais. Brasília: MEC/SEF, 1998.

. Ministério da Educação. Secretaria de Educação Básica. Ciências da natureza, matemática e suas tecnologias: orientações curriculares para o Ensino Médio. Brasília: MEC/SEB, 2 v., 2006.

Fundo Nacional do Desenvolvimento da Educação. Sobre o livro didático:

histórico. Disponível em: http://www.fnde.gov.br/programas/livro-didatico/livrodidatico-historico. Acesso em: 12/09/2013.

CAJUEIRO, R.L.P. Manual para elaboração de trabalhos acadêmicos: guia prático do estudante. Petrópolis: Vozes, 2012.

CANTO, E.L. Ciências naturais: aprendendo com o cotidiano. 3. ed. São Paulo: Moderna, 2009.

CRUZ, J.L.C. (Org.). Projeto Araribá: Ciências. São Paulo: Moderna, 2006.

GEWANDSZNAJDER, F. Projeto Teláris: Ciências. São Paulo: Ática, 2012

GOWDAK, D.O.; MARTINS, E.L. Ciências novo pensar: seres vivos, $7^{\circ}$ ano. São Paulo: FTD, 2012.

KRASILCHICK, M. Prática de ensino de Biologia. São Paulo: Harper \& How do Brasil, 1983.

LUDWIG, A.C.W. Fundamentos e prática de Metodologia Científica. Petrópolis: Vozes, 2009.

MARANDINO, M.; SELLES, S.E; FERREIRA, M.S. Ensino de Biologia: histórias e práticas em diferentes espaços educativos. São Paulo: Cortez, 2009.

NARDI, R.(Org.). Educação em Ciências: da pesquisa à prática docente. 4. ed. São Paulo: Escrituras Editora, 2010.

PEREIRA, A.M.; SANTANA, M. WALDHELM, M. Ciências, $\mathbf{7}^{\mathbf{0}}$ ano: volume 2. São Paulo: Editora do Brasil, 2009.

VASCONCELOS, S.D.; SOUTO, E. O livro didático de Ciências no Ensino Fundamental: proposta de critérios para análise do conteúdo zoológico. Revista Ciência e Educação. [S.I.] v. 9, n.1, p.93-104, 2003.

WALTER, R.; BARRA, C.R. Microbiologia, imunologia, parasitologia. Curitiba: Século XXI, 2001. 